Original Research Paper

\title{
Numerical Simulation of Flexural-tensile Properties of Reinforced Concrete Beam
}

\author{
${ }^{1,2}$ Shi Di, ${ }^{2}$ Wang Juan and ${ }^{1}$ Liu Jianjun \\ ${ }^{1}$ School of Geoscience and Technology, Southwest Petroleum University, Chengdu 610500, China \\ ${ }^{2}$ School of Water Conservancy and Environment, Zhengzhou University, Zhengzhou 450000, China
}

\author{
Article history \\ Received: 06-01-2017 \\ Revised: 07-01-2017 \\ Accepted: 21-01-2017 \\ Corresponding Author: \\ Liu Jianjun \\ School of Geoscience and \\ Technology, Southwest \\ Petroleum University, Chengdu \\ 610500, China \\ Email: liujj0906@163.com
}

\begin{abstract}
Reinforced concrete is a kind of typical composite and reinforced concrete structure is widely used in the construction of a kind of structure, the flexural-tensile properties is very important for structure design optimization. In this study, the 2 dimensional numerical model of reinforced concrete beam is established by using ANSYS software and the effects of the thickness of the protective layer, the reinforcement ratio and the size of the specimen on the flexural performance of reinforced concrete beams are studied. The research shows that the failure of reinforced concrete beams is started in the middle and bottom of the beam and the influence of the specimen size on the failure load is the most significant, the mid-span stress increases with the decrease of thickness of protective layer and reinforcement ratio.
\end{abstract}

Keywords: Reinforced Concrete, Failure Load, Numerical Simulation, Flexural-Tensile and Properties

\section{Introduction}

Concrete is a kind of building material with strong compressive strength but weak tensile ability and its failure is a kind of brittle fracture. Compared to plain concrete, the bearing capacity of reinforced concrete beam which has the same section form, size and concrete strength is much larger and it will produce large deformation before failure. It is because of the advantages of reinforced concrete structure that it has been widely used in water conservancy and hydropower engineering and civil engineering. The mechanical performance of reinforced concrete structure is more complex than that of steel structure, so far there are still many problems remains unsolved, so it is necessary to study the flexural-tensile performance of reinforced concrete. Compared with experiments, numerical simulation software has many advantages. In the structural analysis, the numerical simulation can accurately reflect the mechanical and deformation properties of the whole process, which provides a scientific basis for the optimization of the structure design (Guan, 2010). Meanwhile, the numerical simulation can also be used to copy and reuse the model and can be appropriately modified according to the requirements of different situations, so as to save testing expenses and speed up the process of theoretical and experimental research. In a sense, compared to theory and experiment, numerical emulation can numerical simulation can show the development of things continuously, dynamically and repeatedly and also can make the details of the whole and local development process understood.

There are many research results about numerical simulation research of reinforced concrete structure at home and abroad. Based on finite element method, Deng et al. (2010; Du et al., 2005; Li et al., 2016; Jin and Du, 2012; Du et al., 2012; Mohamed and Hansen, 1999) have carried out numerical simulation about mechanical properties such as uniaxial tension, uniaxial compression and shear-resistance and good results are obtained; Tao et al. (2015) study on stress monitoring and strength analysis of step-by-step translation structure in electric drilling rig; Yu et al. (2015a) Carried out the numerical simulation of casing stress and the influence factors of are analyzed. Tang and Xiang (2015) Yu et al. (2015b) Mohamed and Hansen, (1999) studied the situation of crack penetrating aggregate; Liu (2003) Studied the influence of the thickness of protective layer on the fracture failure; Xu et al. (2014) Wang et al. (2012) Studied the influence of reinforcement ratio on rupture failure; $\mathrm{Hu}$ et al. (2014; $\mathrm{Hu}$ and $\mathrm{Mi}, 2015)$ studied the influence of steel position on rupture failure; $\mathrm{Hu}$ and Mi (2015). Tang (2009), Li et al. (2016) and Licheng et al. (2012) studied the size effect of reinforced 
concrete; Zhang et al. (2007) studied on the difference of mechanical properties of reinforced concrete and plain concrete in loading damage. Wang et al. (2012) treat reinforced concrete beam as a three-phase heterogeneous composites material, analyzing the stress change of longitudinal carrying bar in failure mode and loading process of the beam. Li et al. (2016) treat reinforced concrete column as a three-phase heterogeneous composites material while consider the homogeneity, respectively studied the axial compressive shear failure under macro-scale and axial shear failure under microscale. Guan (2010) carried out simulated model tests of reinforced concrete multi longitudinal beam flume and the numerical model used the three-dimensional nonlinear finite element method, making steels diffused in every unit, calculating the mechanical performance under the load of self-weight, design water level and check water level and the aqueduct is optimized with the goal of the most light self-weight of the structure. Zhong and Liu (2015) in order to describe the heterogeneity of concrete materials better, assuming that mechanical parameters of two phases of concrete two-dimensional planar micromechanical model satisfied with the Weibull probability distribution and the failure of 3 reinforced concrete beams with different shear span ratio were calculated by ANSYS software. Xu et al. (2014) carried out the simulation of shear-compression failure of reinforced concrete beam and the longitudinal rib thickness in the twodimensional model is equivalent to the volume fraction of reinforcement in the original test beam and the failure process of beams is analyzed through Uniaxial compressive stress-strain curve and the external force displacement curve.

In the study of the flexural performance of reinforced concrete, further research is needed in the aspects of influence factors and combining with numerical simulation. In this study, ANSYS numerical simulation software is used to calculate midspan stress and displacement under flexuraltensile load of reinforced concrete and analyze influence of three factors, including layer thickness, reinforcement rate and size, on flexural-tensile performance of reinforced concrete beam.

\section{The Finite Element Model of Reinforced Concrete Beams}

The finite element model of reinforced concrete beams in this study adopts distributed simulation and PLANE182 units are selected for the types of reinforcement and concrete units. The material properties and dimensions of reinforcement and concrete are valued according to the data of Guan Junfeng's 28 pieces of reinforced concrete simply supported beam test and the selection of concrete material is $\mathrm{C} 40$, elastic modulus $32.5 \mathrm{GPa}$ and Poisson's ratio is 0.2 ; the selection of reinforcement is HRB335, taking measured average value of the same samples as elasticity modulus and Poisson's ratio is 0.3 . Three series of models are using planar quadrilateral 4 node elements. The distance between the support center of the original test specimen and the beam-end is $150 \mathrm{~mm}$, that is to say the test beam is simply supported at both ends and the two symmetrical concentrated pressure loading is adopted. The series of test beam with different protection layer thickness and reinforcement ratio are kept pure bending section is $1200 \mathrm{~mm}$, while the series of different section are loaded by $1 / 3$ span.

In this study, the constraint of the model is equivalent to the corresponding node constraint and the load is equivalent to symmetric node concentrated load. For the DP-3 model with reinforcement ratio of $1.4 \%$, its size is $3000 \times 450 \mathrm{~mm}$ and the equivalent thickness of reinforcement is $20 \mathrm{~mm}$, the protection layer thickness is $40 \mathrm{~mm}$ and the concrete tensile strength of this beam is 2.61 MPa. Due to the size of mesh is $20 \mathrm{~mm}$, applying equivalent simply supported constraint of UX and UY on the $120-180 \mathrm{~mm}$ and $2820-2880 \mathrm{~mm}$ node in the bottom of the model and put $\mathrm{Y}$ symmetry equivalent concentrated force at corresponding nodes, respectively $500 \mathrm{~N}$, direction as $\mathrm{y}$ axis negative and ensure pure bending section is $1200 \mathrm{~mm}$, as shown in Fig. 1 .

Due to the original test also studied the similarity ratio of each performance under different proportion, including two-dimensional similar and tri-dimension similar, so this paper only selects part trials of the $\mathrm{BC}$ and DP series for simulation, that is only to study the destruction load of beam under different protection layer thickness and reinforcement ratio. Among them, in this study, the model for the study of the influence factors on the dimensions of the specimen is selected the 3 test beams of HB series, that is to select the size and material property of HB5011, HB5021 and HB5031, this three test beams of section height series in original test. In this study, the longitudinal thickness of the model is based on the equivalent value of the volume fraction of reinforcement in the original test beam, as shown in Table 1.

This paper mainly studies the influence of 3 variables on the flexural-tensile performance of reinforcement concrete, that is different protection layer thickness, reinforcement ratio and model dimension. Among them, the protection layer thickness series is $\mathrm{BC} 20 \sim \mathrm{BC} 70$, respectively $20-70$ $\mathrm{mm}$, a total of 6 sets; the reinforcement ratio series is DP-1 DP-4, respectively 3.0, 2.3, 1.4 and 1.2\%, a total of 4 sets; the model dimension series is HB501 HB503, respectively $1740 \times 240,6000 \times 950$ and $7500 \times 1200 \mathrm{~mm}$, a total of three sets. 


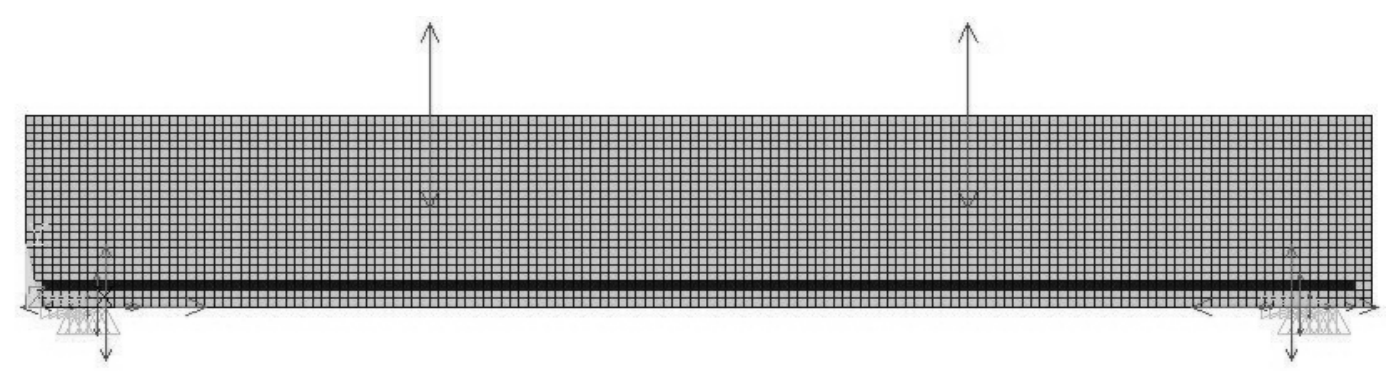

Fig. 1. Loading diagram of DP-3 model

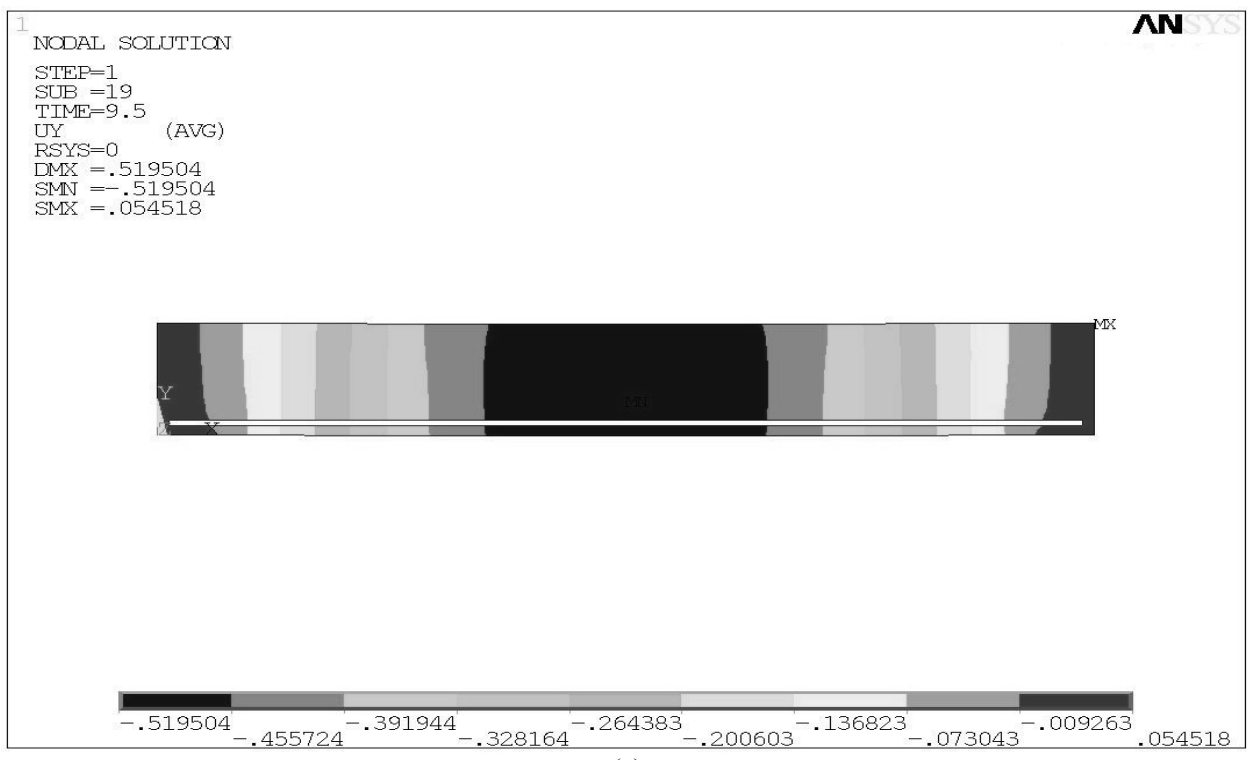

(a)

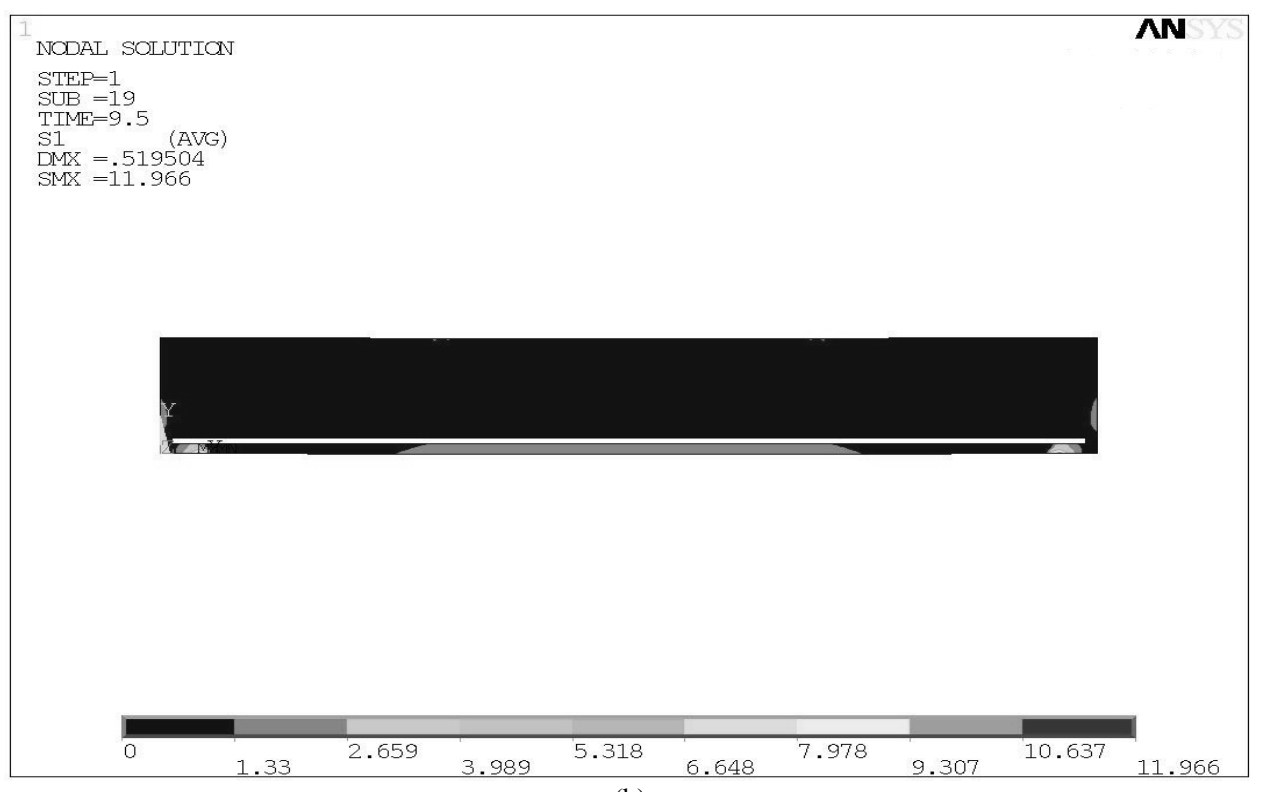

(b)

Fig. 2. Stress nephogram of concrete at grid size $20 \mathrm{~mm}$ (a) Displacement of loading direction (mm) (b) The 1st principal stress $(\mathrm{MPa})$ 
Table 1. Section size of the model and thickness of steel bar and material properties

\begin{tabular}{|c|c|c|c|c|c|c|c|c|}
\hline \multirow{2}{*}{$\begin{array}{l}\text { Number } \\
\text { of models }\end{array}$} & \multirow{2}{*}{$\begin{array}{l}\text { Equivalent } \\
\text { thickness of } \\
\text { steel bars } \mathrm{d} / \mathrm{mm}\end{array}$} & \multirow{2}{*}{$\begin{array}{l}\text { Depth of } \\
\text { section } \\
\mathrm{h} / \mathrm{mm}\end{array}$} & \multirow{2}{*}{$\begin{array}{l}\text { Span } \\
1 / \mathrm{mm} \\
\end{array}$} & \multirow{2}{*}{$\begin{array}{l}\text { Effective } \\
\text { span } 1_{0} / \mathrm{mm}\end{array}$} & \multirow{2}{*}{$\begin{array}{l}\text { Protection } \\
\text { layer thickness } \\
\text { c/mm }\end{array}$} & \multicolumn{2}{|c|}{ Longitudinal carrying bar } & \multirow{2}{*}{$\begin{array}{l}\text { Concrete } \\
\mathrm{fts} / \mathrm{Mpa}\end{array}$} \\
\hline & & & & & & fy/MPa & $\mathrm{Es} / 10^{5} \mathrm{MPa}$ & \\
\hline $\mathrm{BC} 20$ & 20 & 445 & 3000 & 2700 & 20 & 409.36 & 1.92 & 2.64 \\
\hline $\mathrm{BC} 30$ & 20 & 455 & 3000 & 2700 & 30 & 409.36 & 1.92 & 2.64 \\
\hline $\mathrm{BC} 40$ & 25 & 465 & 3100 & 2800 & 40 & 381.14 & 1.90 & 2.61 \\
\hline BC50 & 28 & 475 & 3100 & 2800 & 50 & 399.43 & 1.88 & 2.61 \\
\hline BC60 & 31 & 485 & 3200 & 2900 & 60 & 368.33 & 2.01 & 3.04 \\
\hline $\mathrm{BC} 70$ & 35 & 500 & 3300 & 3000 & 70 & 366.68 & 1.94 & 2.64 \\
\hline DP-1 & 35 & 410 & 2650 & 2350 & 40 & 366.68 & 1.94 & 2.64 \\
\hline DP-2 & 28 & 390 & 2650 & 2350 & 40 & 399.43 & 1.88 & 3.04 \\
\hline DP-3 & 20 & 450 & 3000 & 2700 & 40 & 409.36 & 1.92 & 2.61 \\
\hline DP-4 & 17 & 450 & 3000 & 2700 & 40 & 375.78 & 1.86 & 3.04 \\
\hline HB501 & 17 & 240 & 1740 & 1435 & 50 & 375.78 & 1.86 & 3.04 \\
\hline HB502 & 40 & 950 & 6000 & 5700 & 50 & 399.43 & 1.88 & 3.47 \\
\hline HB503 & 50 & 1200 & 7500 & 7200 & 50 & 366.68 & 1.94 & 3.65 \\
\hline
\end{tabular}

\section{Numerical Simulation of Flexural-Tensile Properties of Reinforced Concrete Beams}

\section{Sensitivity Analysis of Dimensions}

In this study, the study start with BC20 model as an example, sensitivity analysis was carried out on the grid size. The model size is $3000 * 3000 \mathrm{~mm}$, the equivalent thickness of steel $20 \mathrm{~mm}$. By ANSYS before the processor model and define the nature of the material and unit, choose the size of the different meshing model and applied in the same load and constraints. This series are balanced on both sides of the equivalent load of 1 $\mathrm{kN}$, constraint for equivalent node constraint. After loading to solve, after entering the processor, get on the direction of its principal stress and the load displacement variation, such as in Table 2, determined by comparison of cell size of $20 \mathrm{~mm}$, after solving the concrete stress nephogram as shown in Fig. 2.

Analysis and calculation results show that the third principal stress and the displacement change of the three dimensions are small, but the first principal stress decreases gradually increases with the size.

\section{Many Factors Numerical Simulation}

The three series of simulated adopts load step load. Besides HB502 and HB503 two models, the model of symmetrical load by $25 \mathrm{~N}$ increases, the total load by $50 \mathrm{~N}$ increases. Such as DP-3 model, the load step with 20 step loading, in order to solve the menu of the From LS Files after reading load Files to solve, for each step of concrete part across different principal stress and the displacement, such as Table 3 and the model of DP-3 tables can draw the load-displacement diagram, as shown in Fig. 3, we can see loaddisplacement curve is a straight line.

By the first principal stress and the tensile strength of the specimens in the table $2.61 \mathrm{MPa}$, known in step 19 th damage, destroy the symmetry concentrated load is $475 \mathrm{~N}$, the total load of $950 \mathrm{~N}$. Its damage of concrete stress and displacement nephogram as shown in Fig. 4. Figure illustrates the DP-3 reinforced concrete beam damage mainly occurs in the cross beam bottom, as to achieve the maximum of the displacement in the cross.

\section{Reinforcement Ratio Effect on the Flexural-Tensile Properties of Reinforced Concrete Beam}

Until the destruction of concrete under different reinforcement ratio of load-displacement relationship as shown in Fig. 5, load-stress relations as shown in Fig. 6. The figure shows that under the same load, the displacement along with the increase with the decrease of the reinforcement ratio. Model of DP-4 reinforcement ratio is $1.2 \%$, the cross in the largest displacement and the model of DP-1 reinforcement ratio is $3.0 \%$, the minimum displacement across; To cross the stress under the same load, the model of DP-3 reinforcement ratio is $1.4 \%$, the biggest across the stress and the model of DP-1 reinforcement ratio is $3.0 \%$, the smallest across the stress. As the load increased damage to the model, various models of displacement and stress under the same load gap slowly become larger and the gap is more and more obvious. By comparing figures, we can see the stresses of DP-1 and DP-4 have similar magnitude, but the displacement of DP-4 is larger. The reinforcement rate of $1.2 \%$ and $3.0 \%$ when the destruction of the reinforced concrete beam, but the reinforcement ratio was $1.2 \%$ of beam deformation is bigger.

For reinforced concrete beam of different reinforcement ratio, the breaking load, besides DP-3 models, namely, reinforcement ratio of $1.4 \%$ has dropped significantly, Up to $950 \mathrm{~N}$. All the rest of the model of damage load in about $1200 \mathrm{~N}$, floating up and down $50 \mathrm{~N}$. Specimens under different reinforcement ratio when damage occurs across the concrete parts of 
the displacement and stress in Table 4, the stress and displacement of reinforced part in Table 5. You can see from the table of reinforced concrete beams of concrete section first achieve tensile strength and damage occurs, the stress is far from the yield strength of reinforced part.

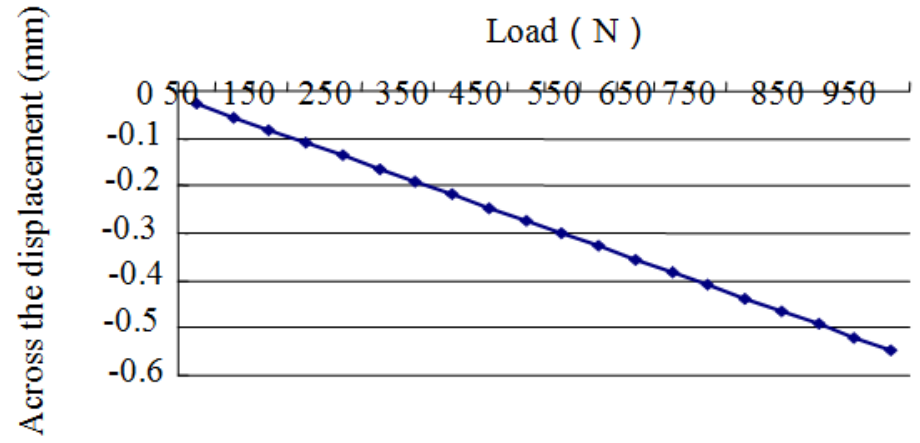

Fig. 3. Relationship between load and displacement of DP-3

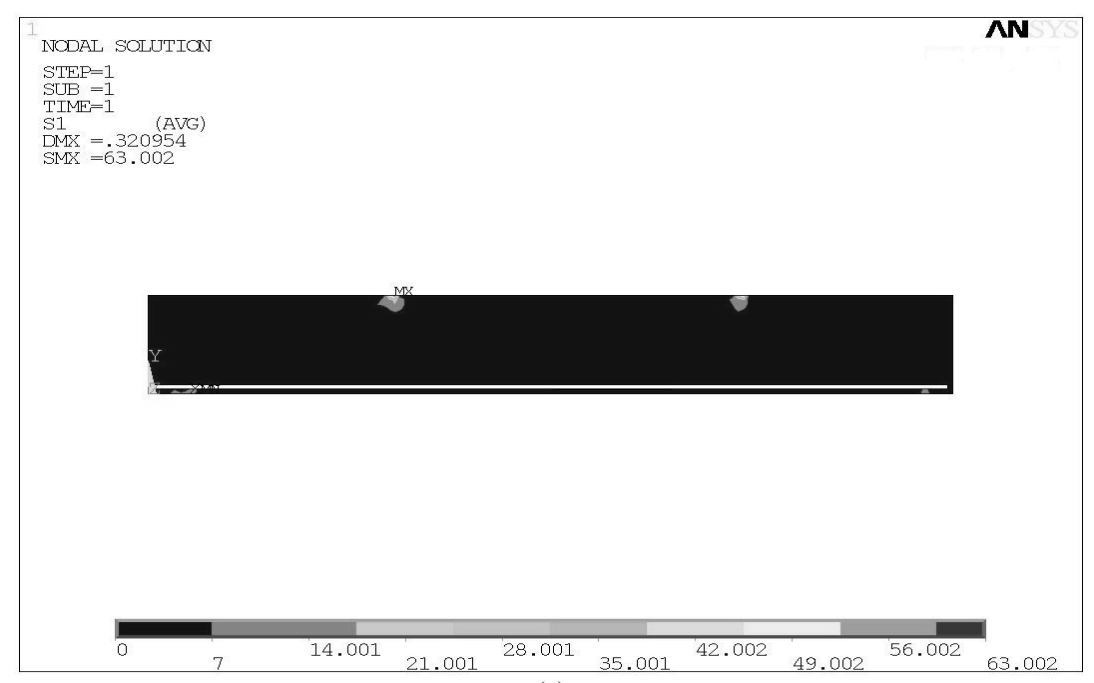

(a)

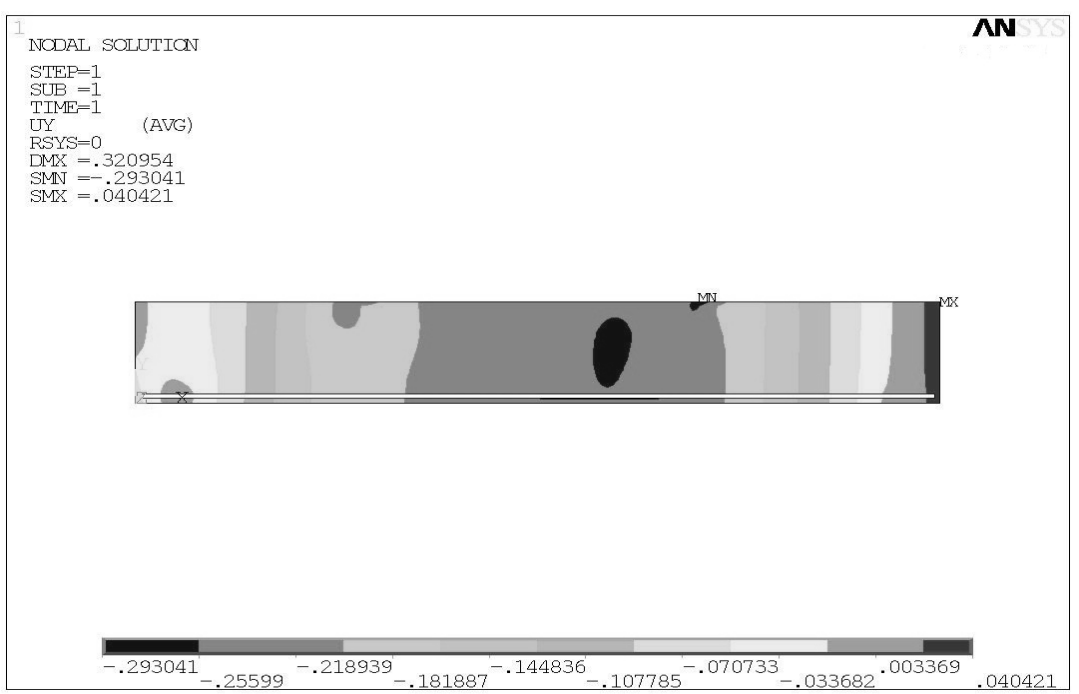

(b)

Fig. 4. Stress and displacement nephogram of DP-3 models (a) The 1st principal stress (MPa) (b) Displacement of loading direction (mm) 


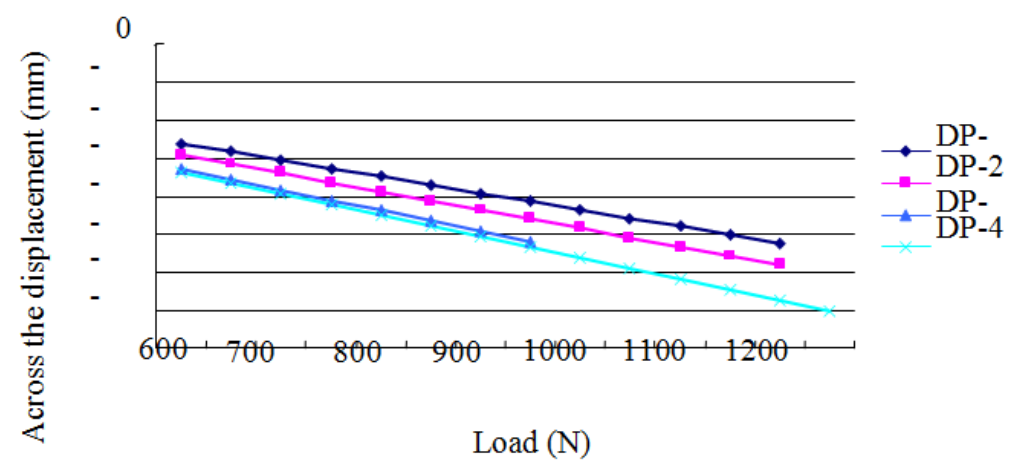

Fig. 5. Load-displacement relation of concrete under different reinforcement ratio

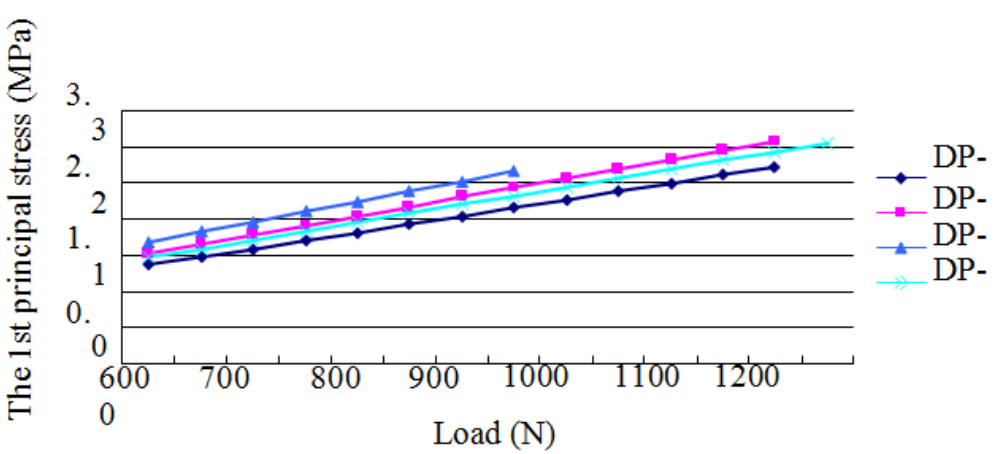

Fig. 6. Load-stress relation of concrete under different reinforcement ratio

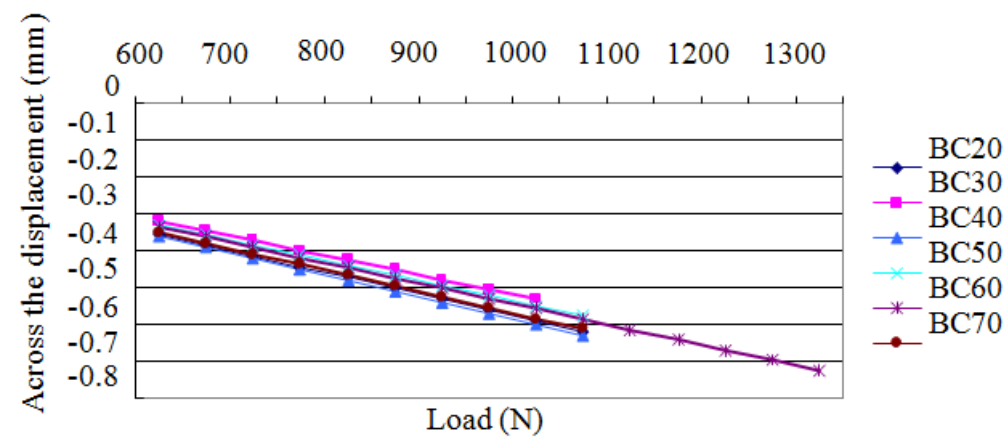

Fig. 7. Load-displacement relation of concrete under different protective layer thickness

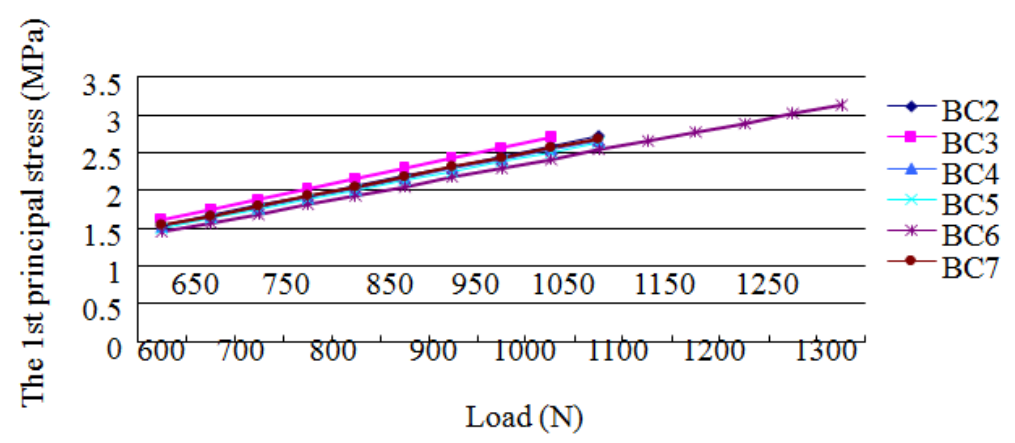

Fig. 8. Load-stress relation of concrete under different protective layer thickness 
Shi Di et al. / American Journal of Engineering and Applied Sciences 2017, 10 (1): 59.68 DOI: 10.3844/ajeassp.2017.59.68

Table 2. Results of the model under different grid sizes

\begin{tabular}{lllllll}
\hline Number & $\begin{array}{l}\text { Grid sizes } \\
(\mathrm{mm})\end{array}$ & $\begin{array}{l}\text { Number of } \\
\text { elements }\end{array}$ & $\begin{array}{l}\text { Number } \\
\text { of nodes }\end{array}$ & $\begin{array}{l}\text { The 1st principal } \\
\text { stress (MPa) }\end{array}$ & $\begin{array}{l}\text { The 3rd principal } \\
\text { stress (MPa) }\end{array}$ & $\begin{array}{l}\text { Displacement of } \\
\text { loading direction }(\mathrm{mm})\end{array}$ \\
\hline 1 & 10 & 13580 & 13934 & 5.307 & -6.383 & -0.01105 \\
2 & 20 & 3648 & 3470 & 4.5 & -6.046 & -0.02093 \\
3 & 40 & 1006 & 1098 & 3.465 & -6.3 & -0.02782 \\
\hline
\end{tabular}

Table 3. Solving results of the model at each load step

\begin{tabular}{lllll}
\hline Steps & Load $(\mathrm{N})$ & Across the displacement $(\mathrm{mm})$ & The 1 st principal stress $(\mathrm{MPa})$ & The 3rd principal stress $(\mathrm{MPa})$ \\
\hline 1 & 50 & -0.02734 & 0.139958 & -0.35275 \\
2 & 100 & -0.05469 & 0.279917 & -0.70549 \\
3 & 150 & -0.08203 & 0.419875 & -1.058 \\
4 & 200 & -0.10937 & 0.559837 & -1.411 \\
5 & 250 & -0.13671 & 0.699792 & -1.764 \\
6 & 300 & -0.16405 & 0.839751 & -2.116 \\
7 & 350 & -0.1914 & 0.979709 & -2.469 \\
8 & 400 & -0.21874 & 1.12 & -2.822 \\
9 & 450 & -0.24608 & 1.26 & -3.175 \\
10 & 500 & -0.27342 & 1.4 & -3.527 \\
11 & 550 & -0.30077 & 1.54 & -3.88 \\
12 & 600 & -0.32811 & 1.68 & -4.233 \\
13 & 650 & -0.35545 & 1.819 & -4.586 \\
14 & 700 & -0.38279 & 1.959 & -4.938 \\
15 & 750 & -0.41014 & 2.099 & -5.291 \\
16 & 800 & -0.43748 & 2.239 & -5.644 \\
17 & 850 & -0.46482 & 2.379 & -5.997 \\
18 & 900 & -0.49216 & 2.519 & -6.349 \\
19 & 950 & -0.5195 & 2.659 & -6.702 \\
20 & 1000 & -0.54685 & 2.799 & -7.055 \\
\hline
\end{tabular}

Table 4. The displacement and stress of concrete during failure

\begin{tabular}{lllll}
\hline Number & $\begin{array}{l}\text { The 1st principal } \\
\text { stress }(\mathrm{MPa})\end{array}$ & $\begin{array}{l}\text { The 3rd principal } \\
\text { stress }(\mathrm{MPa})\end{array}$ & $\begin{array}{l}\text { Across the } \\
\text { displacement }(\mathrm{mm})\end{array}$ & $\begin{array}{l}\text { Tensile } \\
\text { strength }(\mathrm{MPa})\end{array}$ \\
\hline DP-1 & 2.716 & -7.889 & -0.52194 & 1200 \\
FP-2 & 3.061 & -8.33 & -0.58103 & 1200 \\
DP-3 & 2.659 & -6.702 & -0.5195 & 950 \\
DP-4 & 3.047 & -8.705 & -0.70368 & 1250 \\
\hline
\end{tabular}

Table 5. The stress and the displacement of the loading direction

\begin{tabular}{llll}
\hline Number & The 1st principal stress (Mpa) & The 3rd principal stress (Mpa) & Displacement $(\mathrm{mm})$ \\
\hline DP-1 & 9.091 & -27.396 & -0.52191 \\
DP-2 & 9.817 & -28.937 & -0.58097 \\
DP-3 & 10.057 & -24.139 & -0.51928 \\
DP-4 & 13.669 & -33.02 & -0.70332 \\
\hline
\end{tabular}

Protective Layer Thickness Effects on the FlexuralTensile Properties of Reinforced Concrete Beam

For reinforced concrete beam of different protective layer thickness, the load-displacement relationship of until the destruction as shown in Fig. 7, the load-stress relationship as shown in Fig. 8. The figure shows that under the same load, the protective layer thickness of $40 \mathrm{~mm}$, the cross in the largest displacement and protective layer of $30 \mathrm{~mm}$, the minimum displacement across; To cross the stress under the same load, the model of BC30 namely protective layer thickness of $30 \mathrm{~mm}$, the largest across the stress and the thickness of protection layer for 60 mm BC60 namely model, the stress in the least. But both across the displacement and stress in the cross, at the beginning of the load that the load is small, its various model not much of a difference. With the increase of load, various models of displacement and stress under the same load grow big difference, to model to destruction. Comparing figure can see, small amount of $\mathrm{BC} 30$ displacement stress is larger, but its produce BC60 small displacement and stress is small, so the protective layer thickness of $30 \mathrm{~mm}$ than protective layer of reinforced concrete beam is $60 \mathrm{~mm}$ beam damage more easily. 
For different protective layer thickness of reinforced concrete beam, the breaking load you have elevated in the protective layer thickness of $60 \mathrm{~mm}, 1300 \mathrm{~N}$, in addition to the rest of the model of damage load are about $1000 \mathrm{~N}$, the floating up and down $50 \mathrm{~N}$. Specimens under different thickness of protective layer destruction occurs across the concrete parts of the displacement and stress in Table 6, the stress and displacement of reinforced part in Table 7. You can see from the table of reinforced concrete beams of concrete section first reach the tensile strength and produce damage, stress is far from yield strength steel parts.

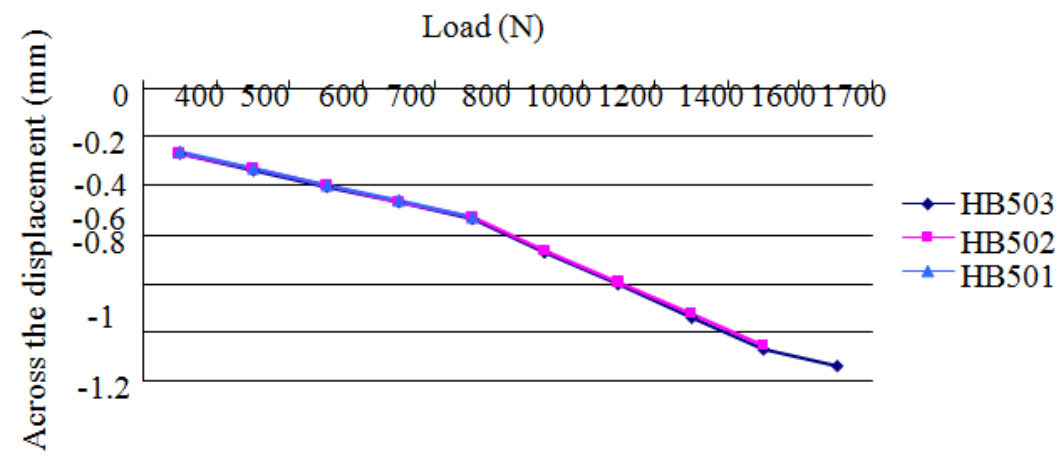

Fig. 9. Load-displacement relationship of concrete under different specimen sizes

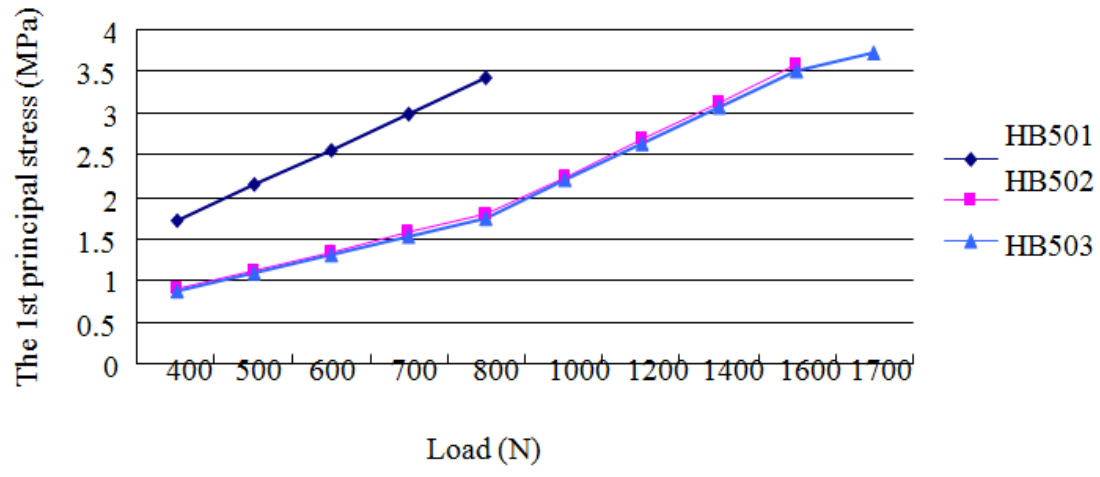

Fig. 10. Load-stress relationship of concrete under different specimen sizes

Table 6. Displacement and stress of concrete during failure

\begin{tabular}{llllll}
\hline Number & $\begin{array}{l}\text { The 1st principal } \\
\text { stress (MPa) }\end{array}$ & $\begin{array}{l}\text { The 3rd principal } \\
\text { stress (MPa) }\end{array}$ & $\begin{array}{l}\text { Across the } \\
\text { displacement (mm) }\end{array}$ & $\begin{array}{l}\text { Failure } \\
\text { load (N) }\end{array}$ & $\begin{array}{l}\text { Tensile } \\
\text { strength (MPa) }\end{array}$ \\
\hline BC20 & 2.716 & -7.717 & -0.6197 & 1050 & 2.64 \\
BC30 & 2.698 & -7.458 & -0.53197 & 1000 & 2.64 \\
BC40 & 2.667 & -7.495 & -0.62884 & 1050 & 2.61 \\
BC50 & 2.628 & -7.54 & -0.57529 & 1050 & 2.61 \\
BC60 & 3.139 & -8.802 & -0.72437 & 1300 & 3.04 \\
BC70 & 2.692 & -7.506 & -0.61247 & 1050 & 2.64 \\
\hline
\end{tabular}

Table 7. The stress and the displacement of the loading direction

\begin{tabular}{llll}
\hline Number & The 1st principal stress (Mpa) & The 3rd principal stress (Mpa) & Displacement (mm) \\
\hline BC20 & 13.427 & -42.517 & -0.61934 \\
BC30 & 11.195 & -30.62 & -0.53169 \\
BC40 & 11.415 & -28.211 & -0.62862 \\
BC50 & 9.565 & -22.872 & -0.57515 \\
BC60 & 11.447 & -26.033 & -0.72426 \\
BC70 & 8.533 & -18.509 & -0.61242 \\
\hline
\end{tabular}


Table 8 . The displacement and stress of concrete during failure

\begin{tabular}{llllll} 
Number & $\begin{array}{l}\text { The 1st principal } \\
\text { stress }(\mathrm{MPa})\end{array}$ & $\begin{array}{l}\text { The 3rd principal } \\
\text { stress }(\mathrm{MPa})\end{array}$ & $\begin{array}{l}\text { Across the } \\
\text { displacement }(\mathrm{mm})\end{array}$ & $\begin{array}{l}\text { Failure } \\
\text { load }(\mathrm{N})\end{array}$ & $\begin{array}{l}\text { Tensile } \\
\text { strength }(\mathrm{MPa})\end{array}$ \\
\hline HB501 & 3.206 & -7.728 & -0.494 & 750 & 3.04 \\
HB502 & 3.579 & -9.959 & -1.058 & 1600 & 3.47 \\
HB503 & 3.73 & -10.031 & -1.139 & 1700 & 3.65 \\
\hline
\end{tabular}

Table 9. The stress and the displacement of the loading direction

\begin{tabular}{llll}
\hline Number & The 1st principal stress $(\mathrm{MPa})$ & The 3rd principal stress $(\mathrm{MPa})$ & Displacement $(\mathrm{mm})$ \\
\hline HB501 & 8.666 & -22.598 & -0.494 \\
HB502 & 12.825 & -33.041 & -1.058 \\
HB503 & 11.685 & -34.291 & -1.138 \\
\hline
\end{tabular}

\section{Specimen Size Effect on the Flexural-tensile} Properties of Reinforced Concrete Beam

The load-displacement relationship of the concrete of different specimen size until the destruction as shown in Fig. 9, load-stress relationship as shown in Fig. 10. The figure shows that under the same load, the displacement of almost no change with the increase of specimen size and to cross the stress, under the same load, model HB501 model into smaller size $1740 * 240 \mathrm{~mm}$, the largest across the stress and the model HB503 namely model $7500 * 1200 \mathrm{~mm}$ for the larger size, the stress in the least. As load increases until model, under the same load stress in the various models across the gap between slowly become larger and because HB501 is differ from HB502 size is larger, the stress in its span is far apart.

For different specimen size, breaking load increases with size has obvious rise. Which model HB501 and HB502 specimen size is large, the breaking load is larger gap, HB502 breaking load of $1600 \mathrm{n}$, probably for HB501 twice; And model HB502 and HB503 specimen size difference is not big, so only a modest increase the breaking load of $1600 \mathrm{n}$ and $1700 \mathrm{n}$ respectively. Under different size specimen damage occurs across the concrete parts of the displacement and stress in Table 8, the stress and displacement of reinforced part in Table 9. You can see from the Table of reinforced concrete beams of concrete section first achieve tensile strength and damage occurs, the stress is far from the yield strength of reinforced part.

\section{Conclusion}

In this study, it establishes the mechanical model of two phase plane by using ANSYS numerical simulation software and analyzes the change of specimen size, stress and displacement in across of the different protective layer thickness, reinforcement ratio and failure load. The study found that the destruction of the reinforced concrete beam are started in reinforced concrete beam across the concrete parts of the bottom and the influence of specimen size on fracture load the most significant. Main conclusions are as follows:

When the protective layer thickness of $40 \mathrm{~mm}$, its across displacement reaches maximum and the protective layer thickness of $30 \mathrm{~mm}$, the across displacement reaches minimum; For the stress in the cross, under the same load, the protective layer thickness of $30 \mathrm{~mm}$, its stress in the cross reaches maximum and protective layer thickness of $60 \mathrm{~mm}$, the stress in the cross is least. For the reinforced concrete beam of different thickness of protective layer, when the protective layer thickness is $60 \mathrm{~mm}$, the failure load has a little rise, up to $1300 \mathrm{~N}$, in addition to the rest of the model of damage in $1000 \mathrm{~N}$ load.

With the increase of reinforcement ratio, the across the displacement of reinforced concrete beam reduces. Under the same load, when the reinforcement ratio was $1.4 \%$, across the stress is biggest and when the reinforcement ratio is $3.0 \%$, across the stress is least. For the reinforced concrete beam of different reinforcement ratio, the failure load, besides the DP-3 model, namely, when the reinforcement ratio is $1.4 \%$, has dropped significantly, up to $950 \mathrm{~N}$, the failure load of the rest model are about $1200 \mathrm{~N}$.

The reinforced concrete beams cross displacement almost don't change with the increase of size. When the model is HB501, namely, the specimen size is smaller $1740 * 240 \mathrm{~mm}$, the across the stress is largest. However, when the model is HB503, scilicet the specimen size is larger $7500 * 1200 \mathrm{~mm}$, across the stress is least. Because of the size difference between HB501 and HB502 is larger; the gap of stress value in its span is larger. For model HB503 and model HB502, they are similar in size, but their stresses in the cross have a gap which is not visible. For different specimen size, breaking load increase significantly with the rise of the size, $950 \mathrm{~N}$, $1600 \mathrm{~N}, 1700 \mathrm{~N}$ respectively.

\section{Acknowledgment}

Financially Supported by the National Natural Science Foundation of China under Grant No.51174170. 


\section{Author's Contributions}

Shi Di: Made considerable cntrubitions to acquisition of data and analysis and interpretation of data, contribured in drafting the article. Give final approval of the version to be subnitted and any revised version.

Wang Juan: Made considerable contrivutions to conception and design. Contribution in reviewing the ariticale ctitically for significant intellectual content.

Liu Jianjun: Contributed in reviewing the article critically for significant intellectual content. Give final appoval of the version to be submitted and any revised version.

\section{Ethics}

This article is original and contains unpublished material. The authors have read and approved the manuscript and no ethical issues involved.

\section{References}

Deng, J., C. Zong and P. Huang, 2010. Interface crack analysis of FRP reinforced concrete beam. Chinese J. Applied Mechan., 01: 553-558.

Du, X., L. Jin and J. Huang, 2012. Concrete mesoscopic fracture failure process simulation based on extended finite element method. Chinese J. Computat. Mechan.

Du, X., Y. Duan and G. Wang, 2005. Continuousdiscontinuous method of concrete fracture. Chinese J. Solid Mechan., 2005: 405-413.

Guan, J., 2010. Theory and application research on simulation model test of reinforced concrete structures. Dalian University of Technology.

$\mathrm{Hu}, \mathrm{S}$. and Z. Mi, 2015. Three-point bend beam reinforced concrete crack propagation process simulation. J. Waterway Eng., 01: 9-17.

Hu, S., L. Jun and X. Fan, 2014. Research progress of concrete damage and fracture performance test. Chinese J. Water Conservancy, S1: 10-18.

Jin, L. and X. Du, 2012. Mesoscopic numerical simulation analysis of reinforced concrete members. Chinese J. Water Conservancy, 10: 1230-1236.

Li, D., L. Jin and X. Du, 2016. Mesoscopic numerical study of axial compression performance and the size effect of Reinforced concrete column. Chinese J. Water Conservancy, 11: 209-218.

Liu, Y., 2003. The application of finite spring method in the reinforced concrete microscomic fracture analysis. Chinese J. Comput. Mechan., 12: 621-626.

Mohamed, A.R. and W. Hansen, 1999. Micromechanical modeling of crack-aggregate interaction in concrete materials. Cement Concrete Comp., 21: 5-6.

DOI: 10.1016/S0958-9465(99)00016-5
Tang, G. and D. Xiang, 2015. Mechanics performance and numerical simulation of the crack surface of the reinforced concrete beam. J. Water Conservancy, 01: 42-50.

Tang, X., 2009. Study on damage and fracture behavior of concrete based on Macro and Meso Mechanics. Tsinghua University.

Tao, Y., G. Tan, J. Wang and C. Ni, 2015. Stress monitoring and strength analysis of electric drill step-type translational structural. J. Southwest Petroleum Univ., 5: 163-169.

Wang, L., L. Xing and Y. Song, 2012. The microscomic numerical simulation study of reinforced concrete beam flexural destruction. Chinese J. Computat. Mechan. Pract., 2012: 934-939.

Xu, Z., N. Jin, J. Chen and X. Jin, 2014. Reinforced concrete beam shear damage analysis basing on extended finite element. Chinese J. Water Conservancy, S1: 130-136.

Yu, Q., T. Yang, S. Tang, H. Liu and Z. Liang et al., 2015a. Three-dimensional reconstruction and application study of quasi brittle materials basing on CT. J. Eng. Mechan., 11: 51-62.

Yu, X., X. Chen and Y. Ji, 2015b. The single factor analysis of the casing stress basing on the numerical simulation. J. Southwest Petroleum Univ., 5: 127-134.

Zhang, J.X., C.A. Tang, Z. Liang, Y. Zhang and Y. Zhang et al., 2007. Numerical simulation of failure process of reinforced concrete specimen under uniaxial tension. J. Computat. Mechan., 2007: 453-458.

Zhong, J. and Z. Liu, 2015. Meso-scale model of reinforced concrete structures and crack propagation simulation. J. Applied Foundat. Eng. Sci., 2015: 1174-1184. 